Editorial

\title{
Los resultados negativos también existen
}

\author{
Andrés Kohan ${ }^{1}$ \\ ${ }^{1}$ Editor Responsable, Revista Argentina de Radiología, Buenos Aires, \\ Argentina
}

Rev Argent Radiol 2020;84:1-2.

En el presente número contamos con la colaboración de Arboleda Gómez DA et al, ${ }^{1}$ quienes han realizado un trabajo retrospectivo, comparando una población de pacientes con tumores renales que han sido embolizados previo a su tratamiento definitivo contra un grupo control. Si bien el objetivo fue describir su experiencia, al leer la introducción y la discusión queda claro que, aunque la literatura es levemente conflictiva y no existe un consenso claro, sí existe un grupo no despreciable de profesionales que coinciden en que la embolización tiene cierta utilidad en cuanto al control hemostático intraoperatorio, las complicaciones postoperatorias y a la duración de la internación post-tratamiento. Esta idea se encuentra alineada con el progreso demostrado en otras áreas de los tratamientos intervencionistas, en las que se han logrado resultados muy buenos en pacientes otrora inoperables. ${ }^{2}$ A pesar de ello, los resultados observados en su serie no logran reforzar hipótesis. Incluso si hay que considerar las limitaciones mencionadas en el trabajo, que podrían haber influido en estos resultados, el artículo es una excelente oportunidad para repasar el sesgo de publicación y el impacto que tiene en la práctica diaria y la vida de los pacientes.

Se conoce como "sesgo de publicación" a la situación en la que los trabajos científicos publicados sistemáticamente en la literatura médica no son representativos de las poblaciones de estudios finalizados. Esto significa que la "evidencia científica" disponible no es un fiel representante de los resultados obtenidos al evaluar todos los estudios realizados en el área en cuestión. ${ }^{3}$

Se considera que uno de los principales motores de este sesgo es la mayor facilidad de publicar estudios con hallazgos positivos en comparación con aquellos trabajos que no han podido demostrar su hipótesis de trabajo. No es una sorpresa entonces observar que la política norteamericana de "publicar o perecer" ("publish or perish"), según la cual el ascenso académico se consigue casi exclusivamente a través del historial de publicaciones -a diferencia de nuestro país y muchos otros de América Latina - ha explotado esta mayor ventaja e impulsado el crecimiento de dicho sesgo. ${ }^{4}$
La importancia del estudio "negativo" es que, si se ha realizado con una metodología adecuada, el mismo debería inhibir a otros investigadores a exponer a nuevos pacientes a líneas de investigación que ya se han probado infructuosas. Incluso se vuelven más relevantes a la hora de evitar que drogas potencialmente peligrosas salgan al mercado, como se ha visto en los polémicos casos del Viox ${ }^{5}$ y los inhibidores selectivos de recaptación de serotonina. ${ }^{6}$

De todas maneras nosotros los editores, y los journals en los que trabajamos, también debemos hacer un debido mea culpa. No es el caso más habitual en nuestra querida RAR, en la que los artículos originales en ocasiones nos han resultado esquivos y por tanto nos esforzamos por acompañar a los autores en la corrección de los mismos para que sean publicables. Pero en revistas que reciben un gran caudal de originales, es comprensible que se prioricen aquellos que podrían permitirles obtener más citas que incrementen el factor de impacto y que, en última medida, son aquellos trabajos que suelen mostrar efectos "positivos" de nuevas terapéuticas o métodos de imagen. Debemos poder reconocer el valor intrínseco de los artículos con resultados "negativos" y la gran importancia de hacerlos disponibles al público en general. Un valor que también debe reconocer el propio autor al recordar que, en un trabajo con una hipótesis sólida y una metodología de trabajo adecuada, la falta de resultados no es un mal resultado.

\section{Bibliografía}

1 Arboleda Gómez DA, Rueda Cárdenas LF, Lopera Valle JS, Vergara Cadavid JA, Hidalgo Oviedo JM. Experiencia de embolización de la arteria renal previa a nefrectomía. Rev Argent Radiol. 2020;84 (01):3-8

2 Arnold MJ, Keung JJ, McCarragher B. Interventional Radiology: Indications and Best Practices. Am Fam Physician. 2019;99(09): 547-556

3 Rothstein HR, Sutton AJ, Borenstein M. Publication bias as a threat to validity. En Rothstein HR, Sutton AJ, Borenstein M, eds. Publication Bias in Meta-Analysis. Prevention, Assessment and Adjustments. John Wiley \& Sons;2005:1-7

\footnotetext{
Address for correspondence Andrés Kohan, Editor Responsable, Revista Argentina de Radiología, Buenos Aires, Argentina (e-mail: andres.a.kohan @gmail.com).
}

DOI https://doi.org/ 10.1055/s-0040-1708831. ISSN 1852-9992.
Copyright (c) 2020, Sociedad Argentina de Radiología. Publicado por Thieme Revinter Publicações Ltda., Rio de Janeiro, Brazil. Todos los derechos reservados.
License terms (1) (1) $\odot \circledast$ 


\section{Editorial}

4 Fanelli D. Do pressures to publish increase scientists' bias? An empirical support from US States Data. PLoS One 2010;5(04):e10271

5 Krumholz HM, Ross JS, Presler AH, Egilman DS. What have we learnt from Vioxx? BMJ. 2007;334(7585):120-123
6 Whittington CJ, Kendall T, Pilling S. Are the SSRIs and atypical antidepressants safe and effective for children and adolescents? Curr Opin Psychiatry. 2005;18(01):21-25 